\title{
Albedo of Glacier AX 010 during the Summer Season in Shorong Himal, East Nepal ${ }^{*}$
}

\author{
Tetsuo Ohata, ${ }^{* *}$ Koichi Ikegami** and Keiji Higuchi**
}

\begin{abstract}
Variations of the albedo on Glacier AX010 were investigated during the summer monsoon season in 1978. In the lower part of the glacier where glacier ice appeared, one of the factors controlling the variation of the albedo is the amount of particulate matter. The albedo decreased in proportion to the increase in the grain size of snow. When the thickness of new snow is smaller than $25 \mathrm{~mm}$, the albedo shows a smaller value than $\mathbf{0 . 8}$ which is the albedo of thick new snow surface. Frequent snowfall and subsequent melting cause large variations of albedo in the summer season, especially in the lower part of the glacier.
\end{abstract}

\section{Introduction}

In the Nepal Himalayas, the largest ablation of glaciers occurs from May to September when the daily average air temperature is above $0^{\circ} \mathrm{C}$. This period roughly corresponds to the monsoon season when much precipitation is observed in this region. Due to low air temperature (the daily average air temperature from June to September is 0 to $4^{\circ} \mathrm{C}$ around $5000 \mathrm{~m}$ ), snowfall is quite frequently on the glaciers. As a result the albedo of the glacier surface changes greatly, on account of the high albedo of new snow. In this paper, the factors determining the albedo, and variations in surface albedo of glacier in the summer season will be reported.

\section{Observation site}

The observations were made on Glacier AX010, which is $50 \mathrm{~km} \mathrm{SW}$ of Mt. Everest (Sagarmatha), in Shorong Himal, East Nepal during the summer season in 1978. The name of this glacier was taken from the glacier inventory compiled by Higuchi et al (1978). The map of the glacier and its environs is shown in Fig. 1. This glacier is the southern most glacier in the Dudh Kund drainage. Glacier AX010 is $1.5 \mathrm{~km}$ long with the mean width of $300 \mathrm{~m}$ in the ablation area and

* Glaciological Expedition of Nepal, Contribution No. 68

** Water Research Institute, Nagoya University, Nagoya 464 (Present affiliation of T. Ohata: National Institute of Polar Research, Tokyo 173)

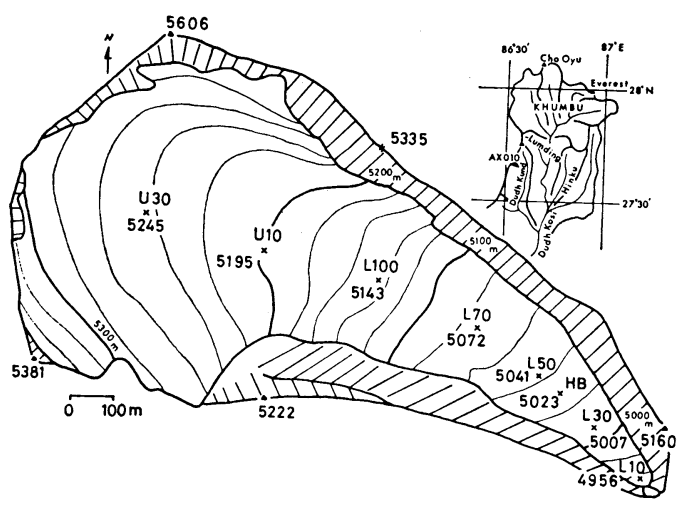

Fig. 1. Map of Glacier AX010. L10 to U30 show the observation sites on the glacier.

$700 \mathrm{~m}$ in the accumulation area. The elevation of the terminus is $4952 \mathrm{~m}$, and of bergshrund is $5360 \mathrm{~m}$, exhibiting the height difference of $408 \mathrm{~m}$. The highest elevation of firn line in 1978 was $5200 \mathrm{~m}$.

As this glacier is located in the southern part of the Nepal Himalayan Ranges, the influence of the monsoon climate can be seen.

The observations of albedo were carried out mainly at 8 sites on the glacier, shown as L10, L30, HB, L50, L70, L100, U10 and U30 in Fig. 1. The elevation of each site is shown in the figure.

\section{Methods of observation}

The albedo of the glacier was obtained by the following two methods.

(a) Pyranometer method (PM method)

The albedo was measured by the pyranometer which was set in parallel with the surface. Most 


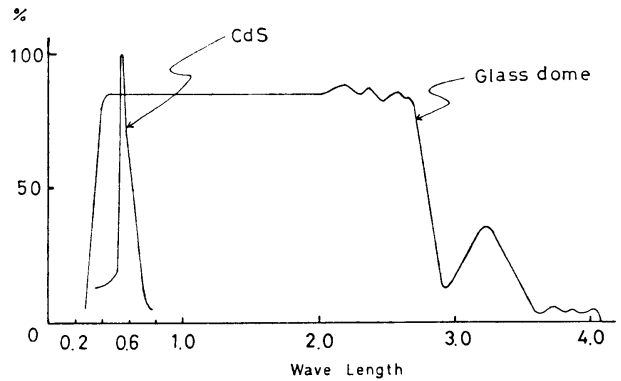

Fig. 2. Transmittance of glass dome of the pyranometer, and spectral response of the CdS cell in the camera.

of the measurements were made between 0.5 and $1.0 \mathrm{~m}$ above the surface. The upward $(S W \uparrow)$ and downward $(S W \downarrow)$ shortwave radiation, that is global radiation, was measured by one or two pyranometers (EKO NEO type). The wavelength dependence of transmission of the glass dome is shown in Fig. 2. The transmittance is flat between 0.3 and $2.0 \mu \mathrm{m}$. The albedo $\alpha$ can be obtained as $\alpha=S W \uparrow / S W \downarrow$.

(b) Exposure-meter method (EM method)

This method is the use of CdS photoelectric sensor in a camera. The camera (Asahi Pentax SP) has a manual exposure-duration time determining system, to keep the amount of light coming onto the film's surface constant. If the meter shows adequate light amount receiving on the film's surface under the condition of shutter speed being $t$ and exposure being $f$, the intensity of the light, $E$, coming on the front surface of the lens will be

$$
E=C f^{2} / t
$$

where $C$ is a coefficient. To obtain the albedo $\alpha^{\prime}, E \downarrow$ from the sky and $E \uparrow$ from the glacier surface should be measured and then calculated $\alpha^{\prime}=E \uparrow / E \downarrow$.

But, there are a few problems in this method. The first is the absorption characteristic of the $\mathrm{CdS}$ as shown in Fig. 2. It has quite a narrow absorption band at $0.5-0.6 \mu \mathrm{m}$. This will give an error on the albedo if the constitution of the wavelength is different between the incident and reflected radiation. According to the review by Mellor (1977), although the reflectance of snow varies with wavelength, there is not much spectral selection in the visible range. The second problem is the dependence of the observed value on the direction to which the optical axis of camera is facing. The value $E \downarrow$ is too large to measure when the sun is in the optical angle of incident light. To avoid this, the observation was made only when the sky was covered by cloud so that the brightness of the sky can be considered as uniform. To obtain $E \downarrow$, measurements were made for three directions, one in the direction of the zenith, and two to the left and right side of the centerline of the glacier at an angle of $20^{\circ}$ from the zenith. To obtain an average value of $E \uparrow 3$ to 5 measurements were made at different places according to the nonuniformity of the glacier surface. To minimize the error caused by these problems, a calibration curve for $\alpha^{\prime}$ was drawn by using the data of $\alpha$ obtained by the PM method.

Fig. 3 shows the relations between the albedo obtained from the PM and the EM methods at the same time for the same surface. In this comparison, the relation is taken for three different topographical conditions of the observation site. One group (a) consists of the sites L10 to L50, another one (b) L70 and the last group (c) L100 to U30. The value $\alpha^{\prime}$ has a good linear relation with $a$. The largest error which is in the last group (c) has a variance of \pm 0.04 . This will be taken as the error for the EM method. The albedo value obtained by the EM method was corrected by the calibration curves in graphs (a), (b) and (c) in Fig. 3.

The EM method seems to be easy in measuring a rough value of albedo at many sites. The equip-
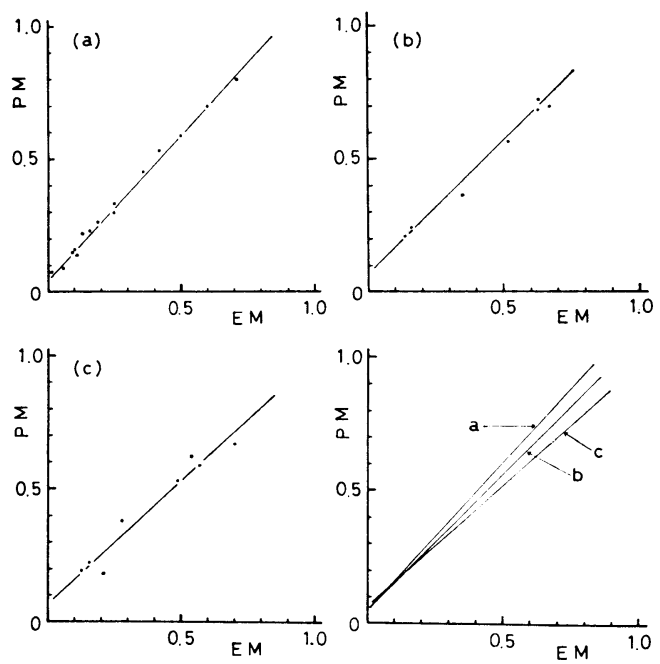

Fig. 3. Calibration curves for the albedo value obtained by the EM method. 
ment is light and preferable to moving usage. The amount of particulate matter increases at However, a calibration curve has to be prepared the lower sites. As seen from this figure, one of according to the topographical situation.

The albedo of a snow or ice surface changes due to the proportion of the direct and diffused shortwave radiation. The study of the diurnal variation of albedo made by Hubley (1957) shows that the albedo increases as solar altitude becomes low, and the albedo is higher under cloudy than clear conditions. In our observations, the EM method was frequently used under cloudy conditions, which means that results obtained here may be a little higher than the average value.

\section{Factors determining the albedo of the glacier}

\subsection{Ice surface}

At the beginning of June in 1978, glacier ice appeared in the lowest part of the glacier. Within one month, the area of bare ice extended to most of the lower half of the glacier, where the albedo varied greatly. The average value of the albedo obtained at each site when the surface was ice will be called the base albedo. This is shown in Fig. 4 which also indicates the amount of particulate matter at the observation sites. At each site, particulate matter was sampled from $50 \times 50$ $\mathrm{cm}^{2}$ area to a depth of $1 \mathrm{~cm}$. The sampling area was selected to have an average dirtiness at each site. The base albedo along the centerline of the glacier varied from 0.33 at $\mathrm{L} 100$ to 0.14 at L10.

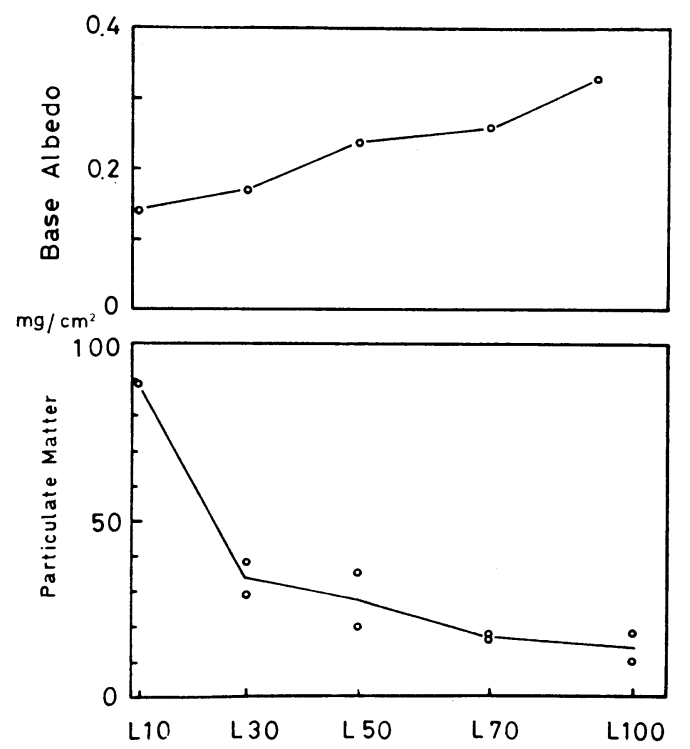

Fig. 4. The value of the base albedo and the amount of particulate matter on the lower part of the glacier.

the important factors which cause the difference in albedo in the ablation area is particulate matter. In addition, the difference in the structure of the ice surface may affect on the albedo. For example, small columnar holes $(0.5-3.0 \mathrm{~cm}$ in diameter and $1-10 \mathrm{~cm}$ in depth) were seen at the surface of the ice after the melting of a temporary snow cover. These surfaces showed a higher albedo of 0.4. These occurred at sites L30 to L70, but not at lower and higher parts.

\subsection{Snow surface}

In case of snow, the albedo is relatively higher than that of ice and can be considered to be determined by factors such as grain size, density, amount of water content in the snow and amount of particulate matter in the surface layer. However, recently Bohren and Beschta (1979) showed that the density of snow does not have a significant effect on the albedo of the snow surface. In addition, when the snow layer is thin, the albedo depends on the albedo of the underlying layers.

The relation between the grain size and the albedo of granular snow is shown in Fig. 5. The data used in this figure were obtained under the following conditions: the air temperature was above $0^{\circ} \mathrm{C}$, and the snow surface had started to melt; the snow layer was not so ripe, less than 10 days after snowfall, and no particulate matter was seen by the naked eye. If the snow layer is less than $25 \mathrm{~mm}$ thick, the underlying layer will affect on the albedo, as discussed later. There-

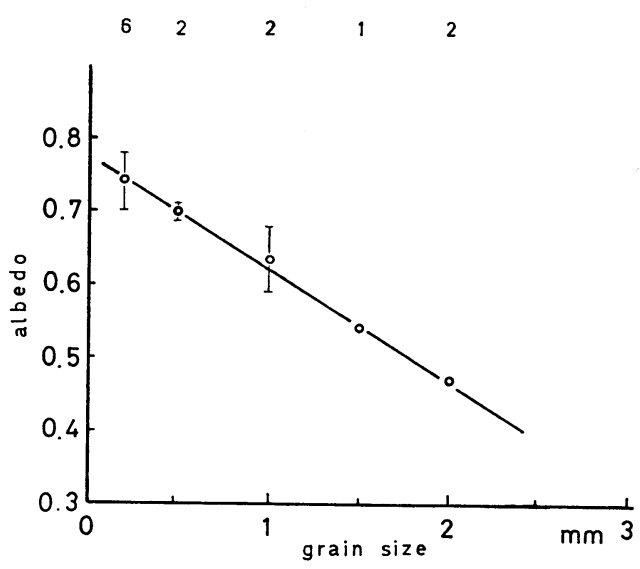

Fig. 5. Relation between the albedo and the grain size of the granular snow. Figures above the diagram indicate the number of samples. 
fore, data obtained on the snow layer more than $25 \mathrm{~mm}$ in thickness were taken. The grain size of the snow was measured by a ruler. In some cases, the grain size was classified into 4 grades, A, B, C and $\mathrm{D}$ with the diameter less than $0.5 \mathrm{~mm}, 0.5$ $1.0 \mathrm{~mm}, 1.0-2.0 \mathrm{~mm}$ and $2.0-3.0 \mathrm{~mm}$ respectively. The mean values of the grain size were plotted in Fig. 5. A linear relation is found between the albedo and the grain size of the snow;

$$
\alpha=-0.16 \phi+0.78 \quad(0.25 \leqq \phi \leqq 2.5 \mathrm{~mm})
$$

where $\phi(\mathrm{mm})$ is the mean grain size of the snow layer. The decrease in albedo occurs as a result of less scattering and more absorption of the incident radiation in the snow layer with large grain size. Our result shows a linear relation with the grain size, but Bohren and Barkstrom (1974) theoretically demonstrated that the albedo is proportional to the square root of the grain size under diffuse illumination.

Snowfall was observed mainly in the nighttime when the probability of occurrence of solid precipitation is high due to low air temperature, and thus a thin new snow cover was often found in the morning. The effect of new snow cover to increase the albedo depends on its thickness. Therefore, to estimate this effect, an index $I(d)$ was defined as

$$
I(d)=\frac{a(d)-a_{b}}{\alpha_{s}-\alpha_{b}} \times 100
$$

where $\alpha(d)$ is the albedo when the thickness of new snow is $d \mathrm{~mm}, a_{s}$ is the albedo of a superimposed medium which is the new snow with the albedo of 0.80 in this case and $\alpha_{b}$ is the albedo of the underlying layer which is taken as the bare ice before snowfall. The albedo of the new snow taken here as 0.80 was the highest value of the thick new snow measured by the PM method during the observation period. $a_{b}$ was not measured for individual cases, but the base albedo shown in Fig. 4 was adopted. Since $\alpha(d)$ depends on $a_{b}, \alpha(d)$ is different with the site even if the thickness of new snow is the same. Therefore, to eliminate this discrepancy, $\alpha_{b}$ is subtracted from both $\alpha(d)$ and $\alpha_{s}$ in the definition of $I(d)$. Then $I(d)$ is normalized to be a value between 0 and 100 .

Fig. 6 shows plots of $I(d)$ against the thickness of new snow at various sites on the lower part of the glacier. $I(d)$ reaches $95 \%$ at $25 \mathrm{~mm}$ of new snow. The thickness of $7 \mathrm{~mm}$ of new snow corresponds to $I(d)=50 \%$. Similar work has been

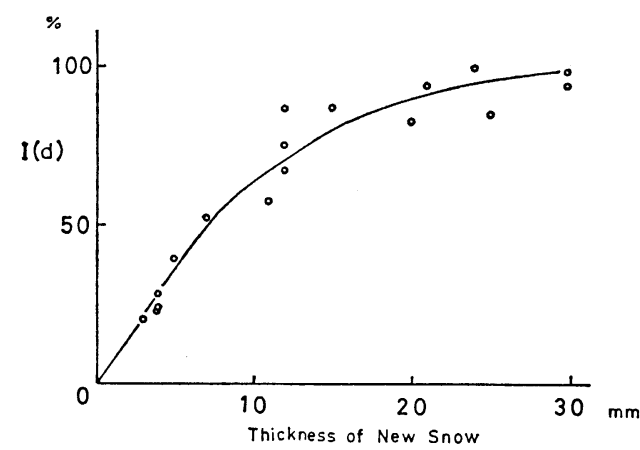

Fig. 6. The effect of the thickness of new snow on the albedo of the glacier surface. See the text for the definition of $I(d)$.

done by Giddings and Lachapelle (1962) experimentally, and the $95 \%$ level in their result was $20 \mathrm{~mm}$ for metamorphosed, homogeneous old snow with a grain size of $0.5 \mathrm{~mm}$. Since the albedo of the thin snow layer was less than 0.80 , it can be said that a part of the incident shortwave radiation is absorbed by the underlying ice surface when the snow layer is thin. If the surface snow layer is thin and the ice temperature is $0^{\circ} \mathrm{C}$, internal ablation will occur at the ice surface.

\section{Variation of albedo}

\subsection{Diurnal variation of albedo}

As described in the previous section, new snow often covered the ice surface on the lower part of the glacier in the morning. As the thickness of snow decreased by melting after the sunrise, the albedo of the surface also decreased as is shown in Fig. 7. The observation was made at L10 on July 23. At 10:40 the albedo was 0.71 under $15 \mathrm{~mm}$ of snow cover. As the snow gradually melted away, the albedo decreased to 0.39 at 14:30 and 0.18 at $17: 30$, when snow of $1 \mathrm{~mm}$ thick covered only $30 \%$ of the surface. Such a diurnal variation in albedo due to new snow accumulation and subsequent melting occurred quite frequently on the lower part of the glacier.

\subsection{Interdiurnal variation of albedo}

The albedo values shown in this section were measured between 8:00 and 12:00. Therefore, they do not show the daily average values. Some of the values were obtained by the PM and the EM methods. Others were obtained indirectly, calculating the albedo from observations of the condition of the ice/snow surface. The calculation was performed by the following procedure: 

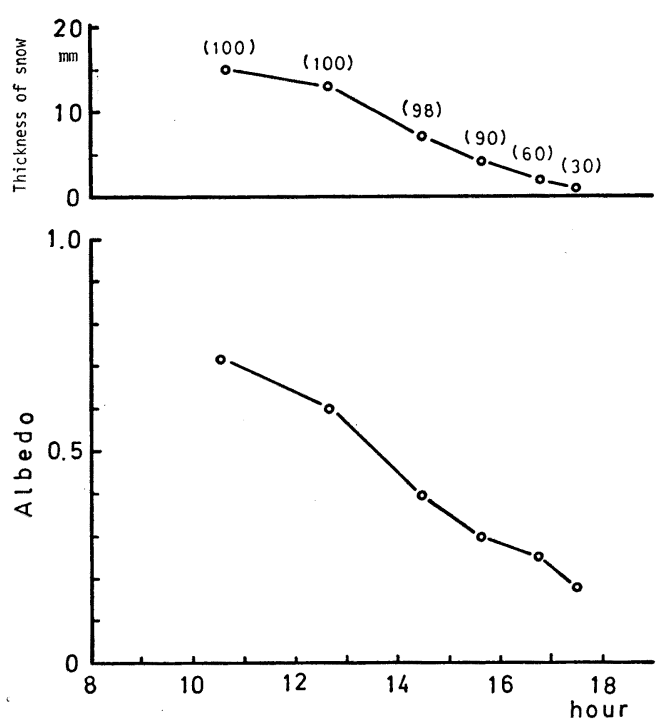

Fig. 7. Diurnal variation of albedo after snowfall at L10 on July 23 . The number in parentheses indicates the percentage of the area covered with snow.

(a) In the case of ice surface, the base albedo shown in Fig. 4 was taken.

(b) If the ice surface was covered with new snow $(\phi<0.25 \mathrm{~mm})$, the following equation derived from equation (3) was used:

$$
a(d)=(I(d) / 100) \cdot\left(\alpha_{s}-\alpha_{b}\right)+\alpha_{b}
$$

where $I(d)$ was obtained from Fig. 6 as a function of the thickness of new snow, $a_{b}$ from Fig. 4, and $a_{s}$ is 0.80 . (c) If the ice surface was covered with granular snow of larger than $0.25 \mathrm{~mm}$ in grain size, equation (4) as well as (b) was used, although this equation is applicable to the case of new snow. However, $\alpha_{s}$ was obtained from equation (2), not 0.80 .

(d) If snow did not cover the ice surface uniformly, the albedo of each ice and snow surface was estimated by the manner mentioned above and then an area weighted mean of albedo was obtained.

The most intense observations were made at $\mathrm{HB}$ and L50 in the center part of the lower half of the glacier, and seasonal variation for the period from May 30 to September 13 is shown in Fig. 8. The observations were made until June 30 at $\mathrm{HB}$ and later at L50, the distance between them was $150 \mathrm{~m}$ and the difference in height was $18 \mathrm{~m}$ as shown in Fig. 1. The glacier surface at the beginning of June was partly ice and partly granular snow, the albedo being around 0.55. Around June 5 , the monsoon weather started at the glacier. Albedo showed quite high values during one period in June, three periods in July and two long periods in August. A heavy snowfall on September 13-14 covered the whole glacier area and after that the albedo remained high. The high albedo values in June, July and August were caused by snowfall which occurred mainly in the nighttime. Sometimes snowfall was observed in the daytime but the snow melted quickly, not giving an effect on the surface albedo. In Fig. 8, the daily maen air temperature at $\mathrm{L} 50$, reduced from the data observed at base camp near the glacier terminus,

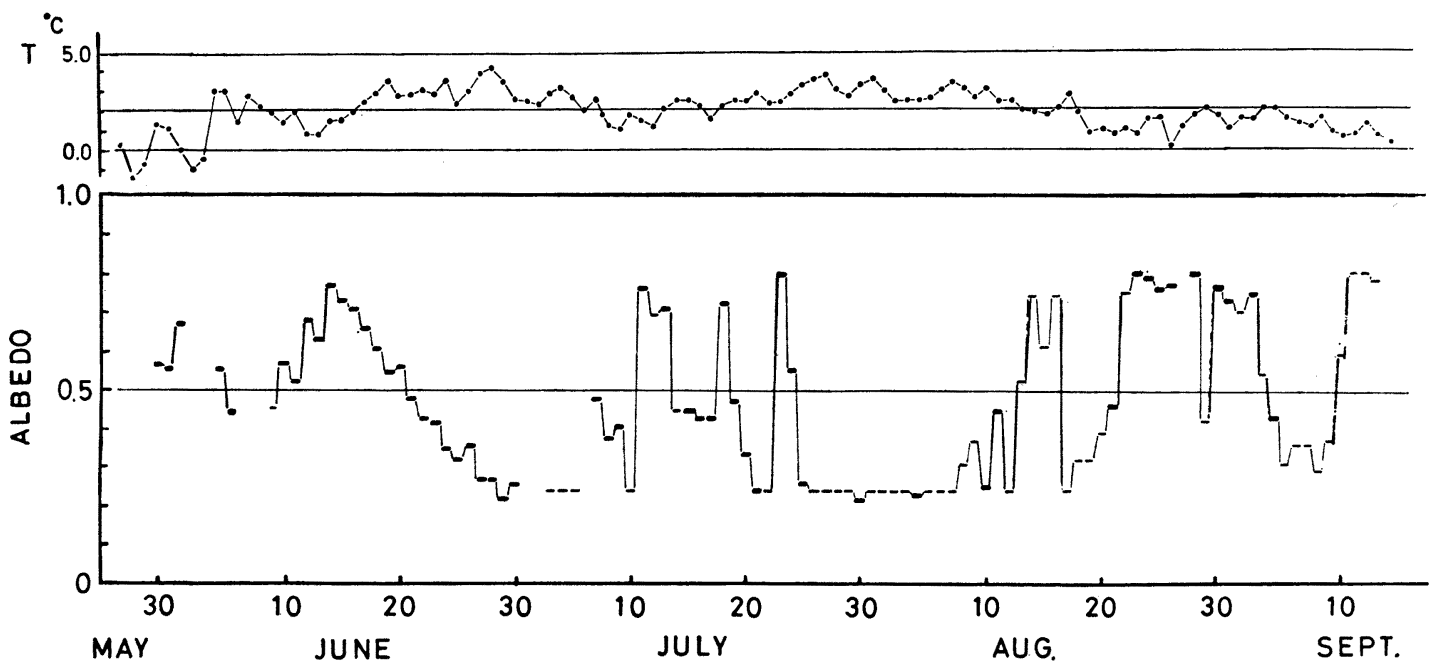

Fig. 8. Variation of albedo at HB (May 30 to June 30) and at L50 (July 3 to Sept. 13). Thick bar: direct measurement. Thin bar: calculated value (see the text). 
is shown with the albedo. Periods of high albedo (above 0.5 ) nearly correspond to the periods of low air temperature (below $2.0^{\circ} \mathrm{C}$ ).

Fig. 9 shows variation of albedo at 7 sites from July 5 to August 5 when detailed observations were carried out. Sites from L10 to L100 are located on the lower part of the glacier, and U10 and U30 on the upper part. The albedo on the lower part shows quite a large variation in comparison with that on the upper part. This is due to the fact that at the beginning of July, the ice surface appeared on the most of the lower part

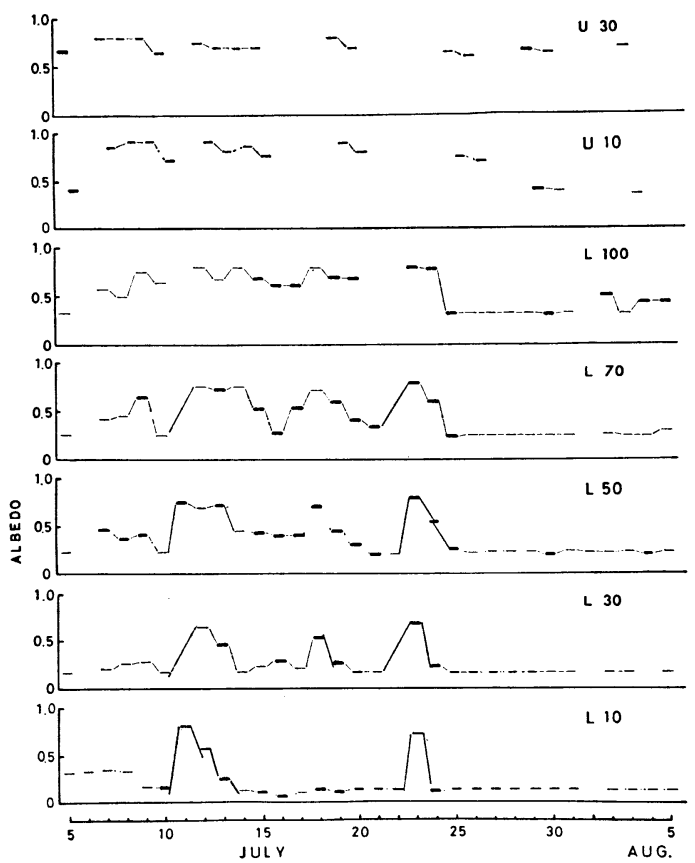

Fig. 9. Variation of the albedo at 7 sites on the glacier from July 5 to August 5 . Thick bar: direct measurement. Thin bar: calculated value (see the text).

while the surface was granular snow on the upper part. Therefore, the effect of snowfall on the albedo was great on the lower part. During this 32-day period, the number of days on which the albedo exceeded 0.5 was 3 days at L10 and L30, 6 days at L50, 10 days at $\mathbf{L} 70$ and 15 days at L100.

On July 23 , the albedo was $0.70-0.80$ at all sites on the lower part of the glacier but the decrease of albedo on the following days was slower at sites of higher elevation. Such difference in the rate of decrease of albedo can be explained by the following two reasons. The first is the difference in the percentage of the solid phase in the total precipitation along the glacier. This percentage depends on the air temperature (Higuchi, 1977; Ageta et al, 1980); therefore, the amount of new snow, causing the albedo to be high, is larger at higher elevations. The second is the speed of ablation, which will be smaller at higher elevation due to lower air temperature. Thus the effect of snowfall on the albedo of the glacier surface remains longer at higher elevations.

\section{Concluding Remarks}

The albedo of the surface of Glacier AX010 varies markedly in the summer season, mainly due to the snowfall. The large change in the albedo due to snowfall was found at lower elevations where the base albedo without snow cover was small. One of the factors controlling the variation of the albedo is the amount of particulate matter on the surface in the ablation area.

The percentage of the net radiation to the total heat source was $87 \%$ at this glacier for two weeks in June as shown by Ohata and Higuchi (1980). Therefore, the difference in albedo will have a strong effect on the whole heat balance, as described in their paper.

Other glaciers in the drainage of Dudh Kosi, where Glacier AX010 is located, are assumed to be under similar conditions of heat balance. However, the degree of the influence of snowfall may depend on the altitude of the glaciers. According to the glacier inventory by the Glaciological Expedition of Nepal (Higuchi et al, 1979), the altitude of terminus of many glcaiers in the southern parts of Dudh Kosi is around $5000 \mathrm{~m}$ as like as Glacier AX010, while most of the debrisfree glaciers in the Khumbu region, which is the upper part of Dudh Kosi, have the altitude of their terminus above $5150 \mathrm{~m}$. Such an altitude of $5150 \mathrm{~m}$ coincides with that of $\mathrm{L} 100$ on Glacier AX010, where the effect of snowfall on the variations of albedo is small. In fact, such glaciers are covered with snow throughout the summer season except near the terminus, as observed on Glacier EB050 (Ageta and Satow, 1978), Glacier CB480 (Fushimi, 1978; Ageta and Satow, 1978) and Glacier ED020 (Ikegami and Inoue, 1978). Therefore, the albedo of these glaciers is always high and free from the influence of snowfall. However, many glaciers in the southern parts of Dudh Kosi, namely, drainages of Dudh Kund Khola where Glacier AX010 exists, I.umding Drangka and Hinku Drangka are considered to be under 
the influence of snowfall similar to that of Glacier AX010.

\section{References}

Ageta, Y. and Satow, K. (1978): Study of mass balance of small glaciers in Khumbu Himal during the summer monsoon season. Seppyo, 40 Special Issue, 4-11.

Ageta, Y., Ohata, T., Tanaka, Y., Ikegami, K. and Higuchi, K. (1980): Mass balance of glacier AX010 in Shorong Himal, East Nepal during the summer monsoon season. in this issue.

Bohren, C.F. and Barkstrom, B.R. (1974): Theory of the optical properties of snow. J. Geophys. Res., 30, 4527-4535.

Bohren, C.F. and Beschta, R.L. (1979): Snowpack albedo and snow density. Cold Region Science and Tech., 1, 47-50.

Fushimi, H. (1978): Stratigraphic studies of Gyajo Glacier, Khumbu Himal. Seppyo, 40 Special Issue, 17-20.

Giddings, J.C. and Lachapelle, E.R. (1961): Diffusion theory applied to radiant energy distribution and albedo of snow. J. Geophys. Res., 66, 181189.
Higuchi, K. (1977): Effect of nocturnal precipitation on the mass balance of Rikha Samba Glacier, Hidden Valley, Nepal. Seppyo, 39 Special Issue, 43-49.

Higuchi, K., Fushimi, H., Ohata, T., Iwata, S., Yokoyama, K., Higuchi, H., Nagoshi, A. and Iozawa, T. (1978): Preliminary report on glacier inventory in the Dudh Kosi region. Seppyo, 40 Special Issue, 78-83.

,,,,,,------- and Takenaka, S. (1979): Glacier inventory in the Dudh Kosi region, East Nepal. Proceedings of the Riederalp Workshop, Sept. 1978, IASH Publ. No. 126, 92-100.

Hubley, R.C. (1957): Measurement of the diurnal variations in snow albedo on Lemon Creek Glacier, Alaska. J. Glacio., 2, 560-563.

Ikegami, K. and Inoue, J. (1978): Mass balance studies on Kongma Glacier, Khumbu Himal. Seppyo, 40 Special Issue, 12-16.

Mellor, M. (1977): Engineering properties of snow. J. Glacio., 19, 15-66.

Ohata, T. and Higuchi, K. (1980): Heat balance study on glacier AX010 in Shorong Himal, East Nepal. in this issue. 